\title{
Mitotic Rate Score 3
}

National Cancer Institute

\section{Source}

National Cancer Institute. Mitotic Rate Score 3. NCI Thesaurus. Code C138985.

A finding of greater than or equal to 8 mitoses per mm2 (greater than 15 per $10 \mathrm{hpf}$ ). 